\title{
Modulation of Tinospora rumphii and Zinc Salt on DNA Damage in Quinoline-Induced Genotoxicity and Hepatotoxicity in Male Albino Mice
}

\author{
Roger Salvacion Tan ${ }^{1,2}$ and Lydia M. Bajo ${ }^{3}$ \\ ${ }^{1}$ Field of Drug Discovery Research, Faculty of Advanced Life Science, Hokkaido University, N21, W10, Kita-ku, Sapporo 001-0021, Japan \\ ${ }^{2}$ Chemistry Department, Xavier University-Ateneo de Cagayan, 9000 Cagayan de Oro City, Philippines \\ ${ }^{3}$ Chemistry Department, College of Science and Mathematics, Mindanao State University-Iligan Institute of Technology, \\ 9200 Iligan City, Philippines \\ Correspondence should be addressed to Roger Salvacion Tan; roj_tan2004@yahoo.com
}

Received 12 August 2014; Accepted 30 October 2014; Published 20 November 2014

Academic Editor: Mugimane Manjanatha

Copyright (C) 2014 R. S. Tan and L. M. Bajo. This is an open access article distributed under the Creative Commons Attribution License, which permits unrestricted use, distribution, and reproduction in any medium, provided the original work is properly cited.

\begin{abstract}
Tinospora rumphii (T. rumphii) is a folkloric medicinal plant that is widely distributed in Asia and Africa. It has been widely used by locals to treat many diseases including jaundice, which is a manifestation of liver damage. We investigated the action of T. rumphii crude extract together with zinc sulphate, a known tumor modulator, on hepatic injuries induced by intraperitoneal (i.p) injections of quinoline on albino mice. The hepatotoxic effect was assessed by bilirubin concentration in the blood serum, while the genotoxic effect was determined by single-cell gel electrophoresis (SCGE). The mice orally fed with the crude extracts, following quinoline exposure, had reduced serum bilirubin concentration and DNA damage. Mice treated with Zinc sulphate, on the other hand, had remarkably reduced DNA damage on hepatocytes. Our findings showed that hepatoprotective potential of T. rumphii extract is dose-dependent and that utilization of the extract as medicinal remedy must be strictly monitored, while zinc was proven to reverse genotoxic effect of quinoline. This study unraveled the potential of T. rumphii extract and zinc as important hepatoprotective agents for future treatment of hepatic damage caused by chemotherapeutic agents used in cancer treatment.
\end{abstract}

\section{Introduction}

Many antineoplastic agents are found and isolated in plants. However, the capacity of nature to produce these agents was not fully exploited by scientists. These are the plants that have long been used in folkloric medicines for treating illnesses. Today, most of the plants that are used in folkloric medicines were found experimentally to have components that are of medical importance. The therapeutic uses of these components are now available in most literatures world-wide.

Tinospora rumphii (Syn. T. Crispa, Menispermaceae) also known as "makabuhai," one of the folkloric medicinal plants that is widely distributed in Asia and Africa, has been used as herbal remedy for a long time $[1,2]$. It is commonly prescribed as an aqueous extract in the treatment of stomach trouble, indigestion, diarrhea, toothache, and topical ulcers
$[3,4]$. In powder form, it is prescribed for fevers, an effective cure for rheumatism, flatulence of children, and jaundice, while the decoction of the stem is reputed to be an excellent remedy for itches and cancerous wounds, and as antimalarial agent $[3,5]$. It was also reported to have stimulatory effect on glucose transporters in mice, may have antidiabetic potential $[6,7]$, and may be a potent antioxidant [8]. A handful of studies on this medicinal plant have been reported. However, its effect on the DNA damage during hepatotoxic and genotoxic exposures to everyday-encountered toxins, for example, quinoline, has never been reported.

Quinoline (Figure 1) is one of the substances being used not only in industrial but also in pharmaceutical production. It is a common compound used as a solvent in the production of some household materials. It is a colorless liquid used as an intermediate in the production of various 
<smiles>c1ccc2ncccc2c1</smiles>

FIGURE 1: Chemical structure of quinoline.

compounds found in cosmetic products (fungicide, antibacterial agents, antiperspirant, and deodorant) including 8hydroxyquinoline, hydroxyquinoline sulfate, and copper-8hydroxyquinolate [9].

Quinoline is also a solvent for resins and terpenes and is used in the production of paints and as an antimalarial medicine [10]. Exposure of rats to quinoline and its derivative compounds either added to their diet or via gastric intubation induced hepatocellular carcinoma [11], hemangioendotheliomas [12], and chromosome aberrations [13] in the livers of rats. Greater incidence of tumorigenesis was also reported when administered by intraperitoneal injection in mice at their early stage of life [14]. The fact that it is being used in the manufacturing industry, as a solvent and as a precursor of some drugs, has caught our interest to study this recently known carcinogen [15].

This study used the crude extract of the stem of "makabuhai" plant [6] and zinc, a reported modulator of tumor size and metastasis in mice and has a reported ability to reduce the extent of DNA damage induced by $\mathrm{H}_{2} \mathrm{O}_{2}$ in normal lymphocytes [16-18], to determine their hepatoprotective effects especially on DNA damage incurred during quinolineinduced genotoxicity and hepatotoxicity in mice.

\section{Materials and Methods}

2.1. Chemicals. All chemicals used were reagent grade. Zinc salt: $\mathrm{ZnSO}_{4}$, quinoline, dimethyl sulfoxide (DMSO), and agarose (low and normal melting) were from sigma. Silymarin (LiverAid) was purchased from a local pharmacy at Cagayan de Oro city, Philippines. All other chemicals were of highest and available commercial grade.

2.2. Plant Sample Extraction. Approximately $1 \mathrm{~kg}$ of air-dried ground stem of Tinospora rumphii was soaked in pure AR grade ethanol for 72 hours. The mixture was filtered and the resulting extract was concentrated to dryness using a rotary evaporator and dissolved in DMSO.

2.3. Ethic Statement. This study was conducted in strict accordance with the recommendations for animal care and handling according to the guidelines set by the National Ethical Guidelines for Health Research of the Philippine National Health Research System, abiding RA number 8485Animal Welfare Act of 1998 and its implementing Rules and Regulations (DA Administrative Order number 40 series of 1998 and the Code of Practice for the Care and Use of Laboratory Animals in the Philippines, 2nd edition, 2002 developed by the Philippine Association for Laboratory Animal Science (PALAS)).
2.4. Experimental Animals. Random breed Swiss albino mice (Mus musculus Lin.) were cultivated in an experimental animal room, biochemistry laboratory at Mindanao State University-Iligan Institute of Technology, Iligan City, Philippines. Seven-week old male mice weighing 20-25 g were used for this experiment. They were housed in plastic cages and were provided standard mice feed and distilled water ad libitum at ambient temperature with a $12 \mathrm{~h}$ light/dark cycle.

\subsection{Determination of Maximum Tolerated Dose (MTD).} Three groups of mice consisting of 5 male mice per group were orally dosed with $0.1 \mathrm{~mL}$ of $500 \mathrm{ppm}, 1000 \mathrm{ppm}$, and 1200 ppm of Tinospora rumphii extract, respectively, and were observed for one (1) week. The highest concentration of the extract treated to a group of mice with zero mortality after this period was set as the MTD.

2.6. Ferric Thiocyanate (FTC) Method. The FTC method used in this study was taken from Aqil et al. [19] In brief, Solution A was prepared by dissolving $4 \mathrm{mg}$ of the extract in $4 \mathrm{~mL}$ of absolute ethanol in a dark screw-capped vial protected from light. The solution was added with $4.1 \mathrm{~mL}$ of $2.52 \%$ oleic acid in absolute ethanol, $8.0 \mathrm{~mL}$ of $0.05 \mathrm{M}$ phosphate buffer (pH 7.0), and $3.9 \mathrm{~mL}$ of distilled water, and then incubated at $40^{\circ} \mathrm{C}$. Mixture with $\alpha$-tocopherol, instead of the extract, was also prepared as positive control, while the mixture without the plant sample was used as negative control. A portion of Solution A $(0.1 \mathrm{~mL})$ was added with $9.7 \mathrm{~mL}$ of $75 \%$ ethanol, $0.1 \mathrm{~mL}$ of $30 \%$ ammonium thiocyanate, and $0.1 \mathrm{~mL}$ of $0.02 \mathrm{M}$ ferrous chloride in $3.5 \% \mathrm{HCl}$ in a dark screw-capped vial protected from light. After 3 minutes of last addition, the absorbance was read at $500 \mathrm{~nm}$ wavelength. The solution was incubated at $40^{\circ} \mathrm{C}$ and the absorbance reading was done every 24 hours until a day after the absorbance of the blank reached its maximum.

2.7. Acute/Single-Dose Quinoline-Induced Hepatotoxicity. Seven-week old male albino mice were used. The animals were assigned to a dosage group ( 5 mice per group) by random grouping. The animals were housed in a plastic cage basket in one room in a $12 \mathrm{hrs}$ light and $12 \mathrm{hrs}$ dark cycle at ambient temperature. The animals were allowed free access to food and water. Quinoline was administered intraperitoneally, while the crude extracts, DMSO, silymarin, and distilled water $\left(\mathrm{dH}_{2} \mathrm{O}\right)$ were administered orally. The control group (T0) received $0.1 \mathrm{~mL}$ of $\mathrm{dH}_{2} \mathrm{O}$ four times at $12 \mathrm{~h}$ intervals and $0.1 \mathrm{~mL}$ DMSO 30 minutes after the first administration of distilled water. Quinoline treated group (TQ) received $0.1 \mathrm{~mL}$ of $\mathrm{dH}_{2} \mathrm{O}$ four times at $12 \mathrm{~h}$ intervals and a single $0.1 \mathrm{~mL}$ dose of $160 \mathrm{mg} / \mathrm{kg}$ quinoline 30 minutes after the first administration of distilled water. The extract treated group 1 (TTE) received $0.1 \mathrm{~mL}$ of $5 \mathrm{mg} / \mathrm{kg}$ crude extract solution (TE) four times at $12 \mathrm{~h}$ intervals and a single $0.1 \mathrm{~mL}$ dose of quinoline (160 mg/kg body weight) 30 minutes after the first dose of the crude extract solution. The extract treated group 2 (TTE/2) received $0.1 \mathrm{~mL}$ of $2.5 \mathrm{mg} / \mathrm{kg}$ body weight crude extract solution (TE/2) four times at $12 \mathrm{~h}$ intervals and a single $0.1 \mathrm{~mL}$ dose of quinoline (160 mg/kg body weight) 
TABLE 1: Schematic representation of acute/single-dose quinoline exposure.

Group

TE: $5 \mathrm{mg} / \mathrm{kg}$ crude extract; TE/2: $2.5 \mathrm{mg} / \mathrm{kg}$ crude extract.

30 minutes after the first dose of the crude extract solution. The silymarin group (TS) received silymarin solution ( $150 \mathrm{mg} / \mathrm{kg}$ body weight) four times at $12 \mathrm{~h}$ intervals and a single $0.1 \mathrm{~mL}$ dose of quinoline $(160 \mathrm{mg} / \mathrm{kg}$ body weight) 30 minutes after the first dose of silymarin solution. The schematic representation of the overall process was shown in Table 1. After thirty-six hours, blood was collected using the cardiac extraction method from all groups. The blood samples were placed in microcentrifuge tubes at room temperature in the dark. Plasma was separated by centrifugation at $2500 \mathrm{rpm}$ at $37^{\circ} \mathrm{C}$ for 15 minutes and directly analyzed for total and direct bilirubin concentrations.

2.8. Blood Collection and Analysis. At the end of the feeding process, $2 \mathrm{~mL}$ of blood from each mouse was collected and put into microcentrifuge tubes protected from light. The blood was allowed to clot and the serum that was separated from the clot by centrifugation was used in determining the biochemical parameters. Total and conjugated bilirubins were determined using protocol and parameters from Atlas Medical [20].

Table 2 reagent solutions were prepared.

Table 3 solutions were pipetted into a cuvette and tubes were mixed and incubated for exactly 5 minutes at room temperature.
TABLE 2

\begin{tabular}{llc}
\hline Reagents & Components & Concentration \\
\hline \multirow{2}{*}{ R1 } & Sulphanilic acid & $30 \mathrm{mmol} / \mathrm{L}$ \\
& Hydrochloric acid (HCl) & $50 \mathrm{mmol} / \mathrm{L}$ \\
& Dimethyl sulfoxide (DMSO) & $7 \mathrm{~mol} / \mathrm{L}$ \\
\hline \multirow{2}{*}{ R2 } & Sulphanilic acid & $30 \mathrm{mmol} / \mathrm{L}$ \\
& Hydrochloric acid & $150 \mathrm{mmol} / \mathrm{L}$ \\
\hline R3 & Sodium nitrite & $29 \mathrm{mmol} / \mathrm{L}$ \\
\hline
\end{tabular}

The spectrophotometer/filter photometer was set to zero with distilled water and each solution was read at $555 \mathrm{~nm}$.

2.9. Chronic/Multiple-Dose Hepatocarcinogenesis. The animals were divided into seven (7) dietary groups: quinoline (TQ), posttreated with TE (TTEp), treated with zinc (TZ), pretreated with TE (pTTE), DMSO (T0), TTE, and TTE/2. For TTEp, the hepatogenotoxicity was induced through intraperitoneal injections (i.p) of quinoline $(80 \mathrm{mg} / \mathrm{kg}$ body weight) three times a week for a period of 4 weeks, after this period, the mice were fed with TE for three weeks. Same routine was done in group $\mathrm{TZ}$ but this time zinc $(2 \mathrm{mg} / \mathrm{kg}$ body weight) was used. Group pTTE was treated three times a week with TE for a period of 3 weeks, after this period, 
TABLE 3

\begin{tabular}{lcccc}
\hline Reagents & Blank for conjugated bilirubin & Conjugated bilirubin & Blank for total bilirubin & Total bilirubin \\
\hline R1 $(\mathrm{mL})$ & - & - & 1.5 & - \\
R2 $(\mathrm{mL})$ & 1.5 & 1.5 & - & - \\
R3 $(\mu \mathrm{L})$ & - & 50 & 1.5 & 50 \\
Sample $(\mu \mathrm{L})$ & 100 & 100 & 100 \\
\hline
\end{tabular}

the mice were given i.p injections of quinoline $(80 \mathrm{mg} / \mathrm{kg}$ body weight) for 4 weeks. TQ is a control group treated with quinoline for seven (7) weeks three times a week. T0 is a control group treated with DMSO for seven (7) weeks three times a week. On the other hand, TTE and TTE/2 groups were fed with TE and TE/2, respectively. All seven treatment groups have free access to food and water ad libitum. After 7 weeks all animals were sacrificed by cervical dislocation.

2.10. Comet Assay [21, 22]. All procedures from here onwards are performed under dim or yellow light with sample container covered with black carbon paper to prevent light exposure.

2.10.1. Cell Isolation. Prior to liver excision of mice, blood was collected through cardiac extraction and serum was analyzed for bilirubin concentration as described above. Livers were excised and homogenized into fine pieces using fine surgical scissors in cold calcium and magnesium free-HBSS (CMFHBSS) containing $20 \mathrm{mM}$ EDTA/10\% DMSO. After all the fine pieces have settled, $5-10 \mu \mathrm{L}$ of cell suspension per $50 \mu \mathrm{L}$ of $0.7 \%$ agarose (cell-agarose mixture) was mixed (prior to addition of cells to agarose, the cells were tested for viability using trypan blue).

2.10.2. Preparation of Microgel Electrophoresis (MGE) Slides. The $50 \mu \mathrm{L}$ of $1 \%$ agarose was placed on the slide at one end and quickly spread evenly with a tip of pipette and let the slides dried horizontally. After drying, $200 \mu \mathrm{L}$ of $1 \%$ agarose was spread onto the previously dried gel, covered with the cover glass, and allowed to solidify at room temperature for 5 minutes. The cover glass was removed and $50 \mu \mathrm{L}$ of the cellagarose mixture was spread onto the first layer of MGE slide and covered with cover glass. The slides were left for drying in 5 minutes. The cover glass was removed and another $200 \mu \mathrm{L}$ of $0.7 \%$ agarose was spread onto each slide and covered with cover glass. The slides were left at room temperature to gel for 5 minutes. Finally, the cover glass was removed and the slides were lowered to the cold freshly prepared lysing solution, protected from light, and refrigerated for a minimum of 1 hour. This procedure was performed under dim yellow light to prevent DNA damage.

2.10.3. Electrophoresis of MG Slides. The slides were removed from the lysing solution and placed side by side in the horizontal gel box near one end, sliding them as close together as possible. The reservoir was filled with freshly made $\mathrm{pH}>13$ electrophoresis buffer until the liquid level

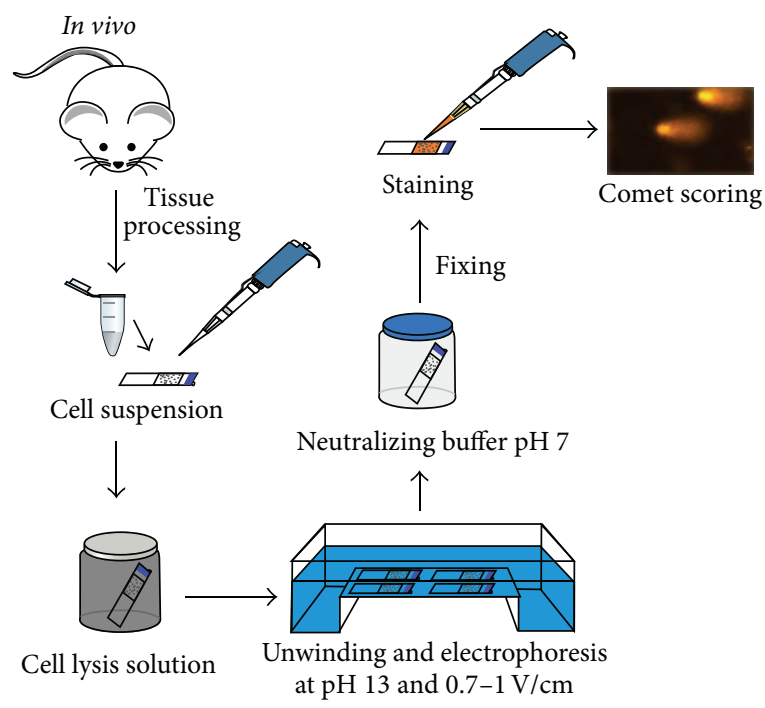

FIGURE 2: Schematic representation of comet assay protocol.

completely covered the slides by avoiding bubbles over the agarose.

The slides were submerged in the alkaline buffer for 20 mins to allow unwinding of the DNA and the expression of alkali-labile damage (ALD). The power supply was turned on to 24 volts and we adjusted the current to 300 milliamperes by raising or lowering the buffer level and then the slides were electrophoresed for 30 minutes. We dipped the slides in neutralizing buffer at room temperature and dehydrated using methanol. Then, the slides were stained using acridine orange $(\mathrm{AO})$ and scored. Figure 2 showed the schematic representation of the single-cell gel electrophoresis method (comet assay).

2.11. Data Analysis. The software used in scoring cells was TriTek CometScore version 1.5. Values were expressed as mean \pm SEM. The DNA damage was indicated by the tail length.

\section{Results}

3.1. Maximum Tolerated Dose (MTD). The MTD was determined to be $1000 \mathrm{ppm}$ of the extract. The percent mortality of groups treated with $500 \mathrm{ppm}, 1000 \mathrm{ppm}$, and $1200 \mathrm{ppm}$ was shown in Table 4 and used to determine the MTD. In this case, $5 \mathrm{mg} / \mathrm{kg}$ body weight was used as the MTD throughout the experiment. 


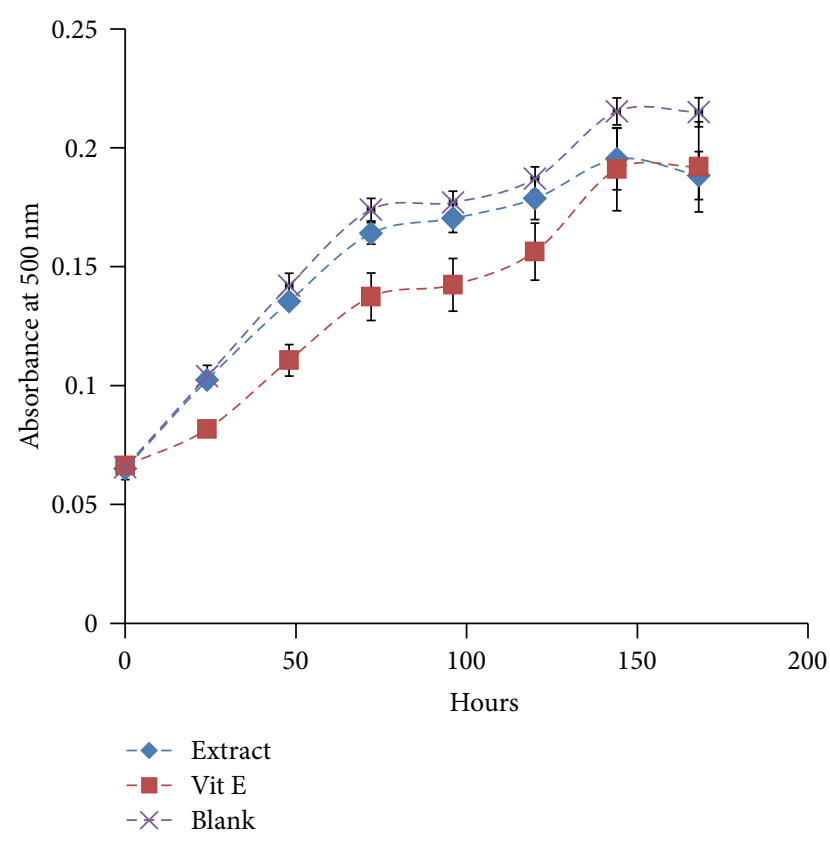

FIGURE 3: Free radical scavenging activity of the ethanolic extract. Values are expressed as mean \pm SEM.

TABLE 4: Number of deaths observed per group after a week of treatment with TCEE.

\begin{tabular}{lcccc}
\hline $\begin{array}{l}\text { Sample } \\
\text { concentration* }\end{array}$ & $\begin{array}{c}\text { Dose } \\
(\mathrm{mg} / \mathrm{kg} \mathrm{bw})\end{array}$ & $\begin{array}{c}\text { Number } \\
\text { of Mice }\end{array}$ & $\begin{array}{c}\text { Number } \\
\text { of dead } \\
\text { mice }\end{array}$ & $\begin{array}{c}\text { Mortality } \\
(\%)\end{array}$ \\
\hline $500 \mathrm{ppm}$ & 2.5 & 5 & 0 & 0 \\
$1000 \mathrm{ppm}$ & 5.0 & 5 & 0 & 0 \\
$1200 \mathrm{ppm}$ & 6.0 & 5 & 1 & 20 \\
\hline
\end{tabular}

${ }^{*} 0.1 \mathrm{~mL}$ of each dose was given per $20 \mathrm{~g}$ mice.

3.2. Free-Radical Scavenging (FRS) Activity. The FRS activity of the extract was determined using the modified ferric thiocyanate (FTC) method. The test was performed to correlate the antioxidant property of the extract to its activity on quinoline-induced DNA damage in the hepatocytes of mice. Figure 3 showed the scavenging activity of the plant extract compared with $\alpha$-Tocopherol (vit E) and the blank. The extract showed lower activity but showed time-dependent scavenging activity as shown on its drastic increase at 144 hours and became similar to vitamin E. The blank, on the other hand, showed the highest absorbance due to increased production of peroxide and thus increased in oleic acid oxidation.

3.3. Acute/Single-Dose Quinoline-Induced Hepatotoxicity. The amount of bilirubin present in the blood serum is an indication of normal or abnormal, if not failure, of the liver activity. Increased bilirubin amount may correspond to an abnormal liver activity and thus is linked to the liver damage. In the present study, bilirubin level was measured as indicator of hepatotoxicity that indicates cellular leakage and loss of functional integrity of the liver cell membrane.

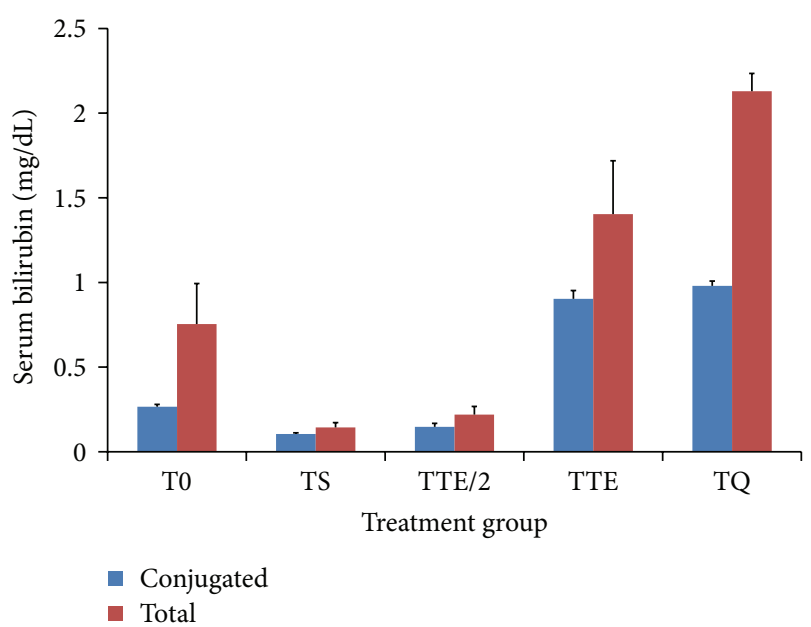

FIGURE 4: Serum bilirubin concentrations in mice after acute exposure to quinoline. T0 = group treated with DMSO (vehicle solvent); $\mathrm{TS}=$ group treated with silymarin $(150 \mathrm{mg} / \mathrm{kg}$ body weight $) ; \mathrm{TTE} / 2=$ group treated with $\mathrm{TE} / 2(2.5 \mathrm{mg} / \mathrm{kg}$ body weight $)$ TTE $=$ group treated with TE $(5 \mathrm{mg} / \mathrm{kg}$ body weight $)$ TQ = group only exposed to quinoline $(80 \mathrm{mg} / \mathrm{kg}$ body weight). Values are expressed as mean. Error bars represent SEM.

Bilirubin concentrations in $\mathrm{mg} / \mathrm{dL}$ present in the blood serum of treated and untreated mice after forty-eight hours vary according to each specific treatment group (Figure 4). Quinoline treated group (TQ), as expected, showed the highest amount of both total bilirubin (tb) and conjugated bilirubin (cb) concentrations with respect to the untreated group (T0). Group TTE has decreased serum tb compared to TQ, although the $\mathrm{cb}$ of both TQ and TTE is similar, indicating that TE might be capable of reducing the tb in serum. However, after treating mice with TE/2 (TTE/2), both serum $\mathrm{cb}$ and tb greatly decreased. This observed decrease is comparable to the action of silymarin (TS), known to have a preventive potential on liver diseases [21].

3.4. Chronic/Multiple-Dose Quinoline-Induced Hepatotoxicity. The multiple-dose quinoline induced hepatotoxicity was performed to determine and compare the effect of multiple exposure of quinoline on mice compared to acute (singledose) exposure. Bilirubin concentrations in $\mathrm{mg} / \mathrm{dL}$ present in the blood serum (Figure 5) of the treated and untreated mice after seven (7) weeks showed that the group pretreated with TE (pTTE) has the highest tb and cb concentrations followed by TQ. Also noticeable was the lower concentration of bilirubin in group posttreated with TE (TTEp), compared to pTTE. Although pTTE significantly lowered the tb concentration, its $\mathrm{cb}$ concentration has no significant difference to that of TQ. Zinc-treated group (TZ), on the other hand, has a remarkable decreased bilirubin concentration in the serum, confirming its capacity to reverse hepatic diseases [1618]. Also, the ratio between the amounts of unconjugated bilirubin (ucb) and cb, in TQ, pTTE, and TTEp groups, was higher compared to groups T0 and TZ. The results showed that pretreatment of the extract might have initially caused 


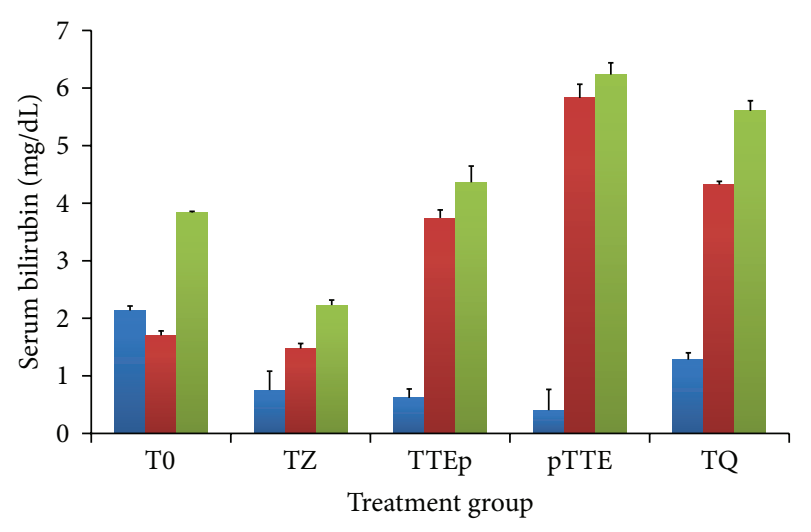

- Unconjugated

- Conjugated

- Total

FIgURE 5: Serum bilirubin concentrations in mice after chronic exposure to quinoline. T0 = group treated with DMSO (vehicle solvent); $\mathrm{TZ}=$ group treated with zinc sulfate $(2 \mathrm{mg} / \mathrm{kg}$ body weight); TTEp = group posttreated with TE $(5 \mathrm{mg} / \mathrm{kg}$ body weight $) ; \mathrm{pTTE}=$ group pretreated with $\mathrm{TE}(5 \mathrm{mg} / \mathrm{kg}$ body weight); TQ = group only exposed to quinoline ( $80 \mathrm{mg} / \mathrm{kg}$ body weight). Values are expressed as means. Error bars represent SEM.

deleterious effect that resulted in a serious hepatic injury prior to quinoline exposure. Posttreatment, on the other hand, might have gradually reduced the hepatic injury caused by chronic quinoline exposure as shown by its decreased amount of tb in the serum. In addition, it also suggested that zinc has the highest hepatoprotective activity citing that the damage caused by quinoline on the liver was greatly reversed as shown by the lowest values of serum bilirubins compared to the extract.

3.5. DNA Damage on Chronic Exposure. Hepatocytes were used to assess the genotoxicity of quinoline, as well as the effect of TE and zinc on quinoline-induced genotoxicity, using the comet assay, a sensitive, rapid, and relatively simple method for detecting DNA damage at the level of individual cells. Results of the visual scoring of total DNA damage observed in hepatocytes, reported here as DNA migration, were illustrated in Figure 6. Significantly higher level of DNA damage was detected in mice exposed to quinoline (TQ), with $70.517 \pm 5.671$ microns, compared to the negative control (T0), with $6.570 \pm 0.260$ microns. Pretreated group showed significant decrease on DNA migration (54.117 \pm 2.724 microns) next to the posttreated group (43.126 \pm 3.035 microns). Zinc-treated group on the other hand, showed almost no significant DNA damage (6.738 \pm 0.132 microns), compared to the rest of the quinoline exposed groups, and its DNA migration was almost similar to T0. The results suggested that zinc exhibited the strongest hepatoprotective potential compared to the crude extract (pre- and posttreatments). Between the two treatment groups (pTTE and TTEp), TTEp exhibited highest ability in decreasing DNA damage in the liver.

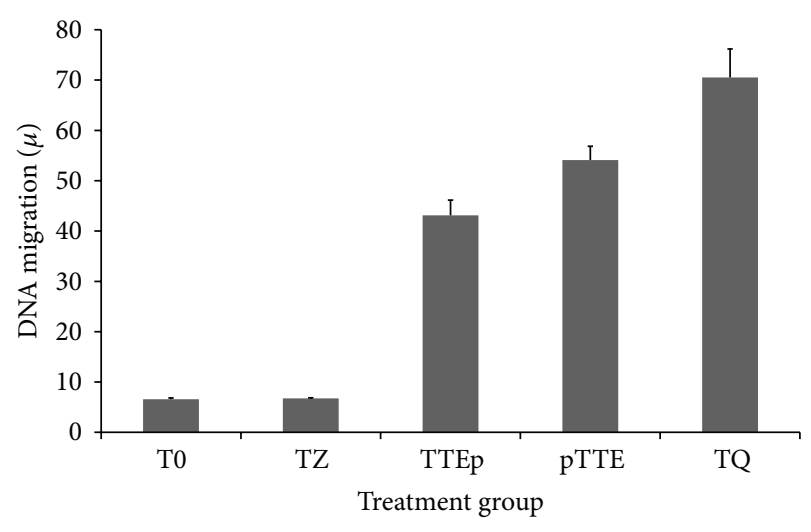

FIGURE 6: Summary of DNA migration in quinoline-induced hepatic genotoxicity evaluated by comet assay. Two-hundred-fifty comets were counted in each group (50 comets per animal). Values are expressed as mean. Error bars represent SEM. T0 = group treated with DMSO (vehicle solvent); TZ = group treated with zinc sulfate $(2 \mathrm{mg} / \mathrm{kg}$ body weight $) ;$ TTEp = group posttreated with TE $(5 \mathrm{mg} / \mathrm{kg}$ body weight); $\mathrm{pTTE}=$ group posttreated with TE $(5 \mathrm{mg} / \mathrm{kg}$ body weight $)$;Q = group treated with quinoline $(80 \mathrm{mg} / \mathrm{kg}$ body weight $)$.

\section{Discussions}

The fact that quinoline can induce hepatocellular carcinoma and chromosomal aberrations in the liver [11-14], the use of this compound, not only in industrial but also in pharmaceutical production, including household materials and cosmetic products, threatens more humans that had been exposed to this compound [10]. Although high technologies medical care are available worldwide, giving more and more people access to excellent health care services, many people especially from developing countries still have no access to this 21 st century health care technology and only rely on herbal medicines from medicinal plants available in their backyards. Information on therapeutic potential of these medicinal plants, although most of them are not scientifically vetted, has been circulating and is being passed on from generations to generations.

T. rumphii is one of the medicinal plans widely known in Asia and Africa to have a therapeutic potential against several types of illnesses [1-8], although this matter remains somehow controversial. Furthermore, T. rumphii has a bitter component, columbine [8], and is administered by the locals in decoction form without proper regulation.

This study assessed the effects of ethanolic extract of $T$. rumphii in treating acute and chronic quinoline-induced liver damage on mice. Our results showed that acute quinoline exposure can cause deleterious effect on the liver as indicated by the highest bilirubin concentration found in the serum of quinoline exposed mice (Figure 4). This result is consistent with the previous studies about the hepatotoxic activity of quinoline and quinoline compounds; the mechanism in which the quinoline damages the liver is linked to its activity to bind to the nitroso-compounds in the liver but the overall mechanism is still not certainly known [11-13]. The quinoline metabolites in the liver may also react with liver enzyme and form a free radical; the free radical metabolites then induced 


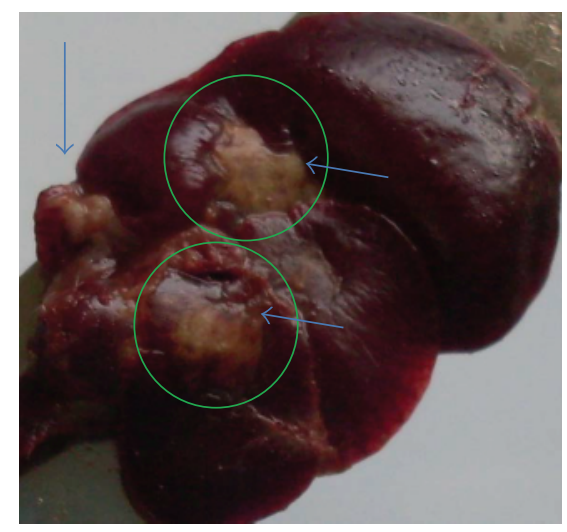

FIGURE 7: Representative fatty liver found in mice after quinoline exposure. Blue arrows point the area with fatty globules. Areas inside green circles are area in the liver with higher fat globule formations.

the liver damage, which would cause lipid peroxidation and disrupting the integrity of the hepatocellular membrane [22]. These findings were supported by the presence of fatty tissues on the liver of the mice observed in this study (Figure 7).

After quinoline exposure, treatment with TE on mice showed a significant decrease in the serum tb. When the amount of TE administered to the quinoline exposed mice was reduced (TE/2), remarkable decrease on both serum cb and tb were observed. These decreases were comparable to silymarin treated group (TS). The results suggested that TE/2 has the highest hepatoprotective capacity compared to TE. $\mathrm{TE} / 2$ and silymarin are both effective in reversing hepatocyte injury caused by exposure to quinoline. Although TTE has decreased amount of $t b, c b$ has fairly no change compared to TQ.

Bilirubin is a product of red blood cell $(\mathrm{rbc})$ degradation as a consequence of reaching to a senescence state [23]. This bilirubin product is in unconjugated form. The unconjugated form is then transported to the hepatic microsomes and converted to its conjugated form via an ester linkage with sugar moieties through the action of uridine diphosphateglucuronyltransferase (UDP-GT); this conjugated form is then pass through the bile for clearance of bilirubin from the system [24]. Failure of conjugation caused by defective liver could be manifested in an increased amount of ucb in the serum and is called unconjugated hyperbilirubinaemia. On the other hand, an increase in the amount of $\mathrm{cb}$ in the serum leads to conjugated hyperbilirubinaemia [25]. The $t b$ is the sum of $\mathrm{cb}$ and ucb in the serum, which means that TTE has the lowest ucb amount compared to TQ (Table S2 in Supplementary Material available online at http://dx.doi.org/10.1155/2014/201762). This could indicate that the impaired conjugation process in $\mathrm{TQ}$, indicated by high ucb amount, might have been reversed after treatment with TE. Treatment with silymarin and TE/2 evidently showed remarkable hepatoprotection as shown by the increased cb with respect to the tb amount, as well as their rapid clearance from the system compared to the rest of the treated groups (Figure 4).

Several mechanisms have been proposed regarding the role of quinoline in inducing liver damage. One of these mechanisms is the conversion of quinoline to its active water-soluble quinoline intermediate metabolite, which is quinoline-2,3-epoxide $[26,27]$. In a study conducted by Cowan et al. [28], a cDNA-expressed human microsomal epoxide hydrolase was shown to efficiently convert the epoxide to the diol which may also be possible in mice [22]. This could be correlated to the scavenging activity of TE compared to vitamin E (Figure 3). Although at 48 hours (within the duration of acute exposure treatment) the FRS activity is negligible, its activity increased as the incubation time increased, suggesting a possible FRS antagonism in the crude extract in which as free radicals increased though time the FRS antagonist might have been degraded or incapacitated unveiling a strong FRS activity in effect. This suggested that its hepatoprotective mechanism may increase through time and its initial FRS activity may not be due to its ability to directly combine with free radicals but may be due to other mechanisms such as inhibition of radical formation or membrane stabilization. This result was also consistent with the findings from the study of Lin et al. in 1997 that TE reduced the liver damage induced by rifampicin [29].

In the chronic hepatoxicity study, bilirubin concentration in the blood serum also varied according to each specific treatment group. The results showed consistent high bilirubin amount in quinoline treated group. As shown in Figure 5, $\mathrm{cb}$ ratio with respect to the tb and ucb was very high, which was an indication of the development of conjugated hyperbilirubinaemia [23-25]. This increase in cb could be an indication that chronic quinoline exposure may have caused impairment in hepatobiliary functions. The hepatobiliary activity is the one that secures the proper clearance of $\mathrm{cb}$ through bile excretion [23]. Bile excretion of $c b$ is the most susceptible step and is most disturbed leading to conjugated hyperbilirubinaemia due to the efflux of conjugates back to the plasma [23]. Pre- and posttreatments were performed in order to determine if TE has preventive activity against quinoline-induced hepatotoxicity. Pretreatment (pTTE) produced higher bilirubin concentrations compared to posttreatment (TTEp) indicating that TE has no preventive effect towards hepatotoxicity. The high amount of both tb and cb in pTTE may indicate that TE has cytotoxic effect on the liver and or may have potentiated the hepatotoxic effect of quinoline [30]. However, when TE was administered after the induction of hepatocyte injury a decreased bilirubin concentration was observed. It could be deduced from this trend that pretreatment with TE prior to the exposure of quinoline could intensify the hepatic injury, while posttreatment of TE may incur hepatoprotection. The results of the chronic hepatotoxicity study suggested the same findings in the study of Chavalittumrong et al. in 1997 [31] that prolonged use of high doses of TE could also cause liver and renal toxicities.

Moreover, zinc showed significant hepatoprotection on mice, as shown in its reduction of bilirubin amounts in the serum. Very low concentration of ucb in the serum as a consequence of higher $\mathrm{cb}$ counterpart could be an indication that UDP-GT activity may not be affected by quinoline exposure in the liver, but rather only the transport of $\mathrm{cb}$ from the liver to the bile is impaired. 


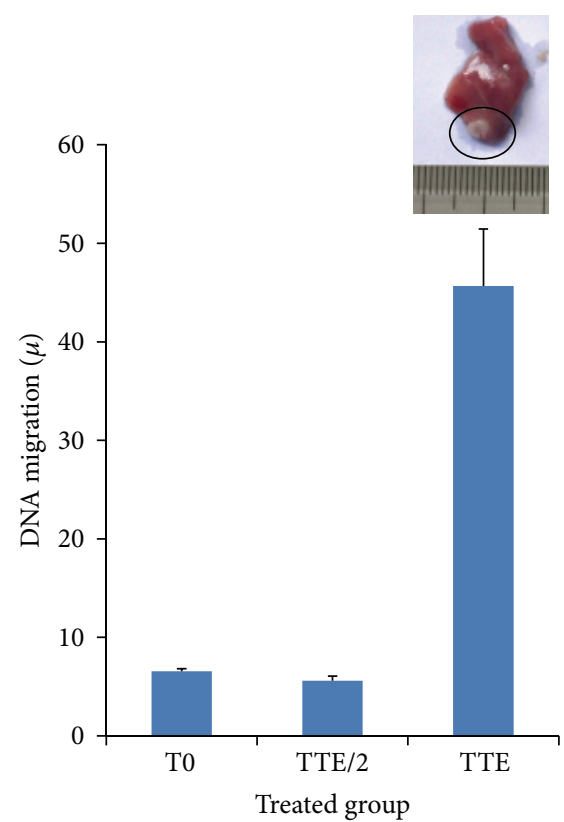

FIGURE 8: Summary of DNA migration in hepatocyte of mice treated with ethanolic extract alone for 7 weeks and representative picture of white tumor found in the liver of mice treated with TE (inset). Values are expressed as mean \pm SEM. T0 = group treated with DMSO (vehicle solvent); TTE = group treated with TE $(5 \mathrm{mg} / \mathrm{kg}$ body weight $)$ TTE $/ 2$ = group treated with $\mathrm{TE} / 2(2.5 \mathrm{mg} / \mathrm{kg}$ body weight).

We examine the correlation between results in the hepatotoxicity to genotoxocity and if the effects of TE and zinc on hepatotoxicity can be really extended to genotoxicity. The DNA damage in hepatocytes induced by chronic exposure of quinoline was assessed using SCGE. After cardiac extraction of blood from the treated and untreated mice, the livers were excised, homogenized, and analyzed for DNA damage.

Result revealed that, in connection to its strong hepatoprotective capacity, zinc exhibited the strongest repair to DNA strand breaks compared to the crude extract in pre- and posttreatment. Consistent with the bilirubin assay, posttreatment incurred higher DNA damage reduction compared to pretreatment.

Zinc deficiency was reported to cause oxidative DNA damage and chromosome breaks in animals [32] and provides defense against free radicals, maintaining genomic stability $[15,33]$. The observed activity of zinc in this study could also be attributed to its protective effect on normal cells [15].

To check the effect of the extract alone on hepatocyte DNA, TE, and TE/ 2 were fed to the group of mice for 7 weeks. The result depicted in Figure 8 showed that TE can induce DNA damage on mice treated chronically. However, mice treated with TE/2 showed no DNA damage.

The result suggested that the extract exhibited significant reduction of DNA damage in the liver during posttreatment compared to in the pretreatment and that the use of this extract for disease prevention might be problematic.

The therapeutic effect of the extract is concentrationdependent and must be taken with caution and strict supervision. This increased DNA migration pattern in mice treated with TE was validated by a visible formation of white tumours in the liver of the mice (Figure 8 inset) but not in TE/2 treated group. This further signified the carcinogenic effect of the extract at higher concentration. While at lower concentration, the extract has the highest therapeutic efficiency that could outweigh its effect when taken at higher concentration. The presence of a white tumor mass in two out of five mice treated with TE was probably due to the intense hepatotoxic effect of the extract as a result of prolonged/chronic exposure [31]. These results were also consistent with the serum bilirubin findings in the previous section.

\section{Conclusion}

Results from this study clearly indicated that the extract from Tinospora rumphii has a dose-dependent modulating capacity towards hepatotoxicity and hepatic genotoxicity induced by quinoline in both acute and chronic exposure, and therefore its utilization must be strictly monitored. Zinc sulphate can remarkably reverse hepatotoxicity and genotoxicity, which proved the highlight of its importance as hepatoprotective agent on hepatic damages caused by chemotherapeutic agents in cancer treatment.

\section{Conflict of Interests}

The authors declare that there is no conflict of interests regarding the publication of this paper.

\section{Acknowledgment}

The authors would like to express their gratitude to the Department of Science and Technology-Philippine Council for Advanced Science and Technology Research and development (DOST-PCSTRD) for the graduate scholarship grant and research funding.

\section{References}

[1] C.-T. Ruan, S.-H. Lam, T.-C. Chi, S.-S. Lee, and M.-J. Su, "Borapetoside C from Tinospora crispa improves insulin sensitivity in diabetic mice," Phytomedicine, vol. 19, no. 8-9, pp. 719724, 2012.

[2] L. R. Zafinindra, W. Diatta, A. M. Dieye, R. Nongonierma, B. Faye, and E. Bassene, "Antipyretic effect of aqueous extract and alcaloid of Tinospora bakis (Miers) in rabbits," Dakar Medical, vol. 48, no. 1, pp. 29-33, 2003.

[3] E. Quisumbing, Medicinal Plants of the Philippines, pp. 300-301, Bureau of Printing, Manila, Philippines, 1951.

[4] J. Concha, Philippine National Formulary (Medicinal Plants), National Science Development Board, Manila, Philippines, 1982.

[5] L. S. De Padua, G. C. Lugod, and J. V. Pancho, Handbook on Philippine Medicinal Plants, Documentation and Information Section, Office of the Director of Research, University of the Philippines at Los Banos, Manila, Philippines, 1981. 
[6] C. Murakami, K. Myoga, R. Kasai et al., "Screening of plant constituents for effect on glucose transport activity in Ehrlich ascites tumor cells," Chemical and Pharmaceutical Bulletin, vol. 41, no. 12, pp. 2129-2131, 1993.

[7] H. Noor and S. J. H. Ashcroft, "Antidiabetic effects of Tinospora crispa in rats," Journal of Ethnopharmacology, vol. 27, no. 1-2, pp. 149-161, 1989.

[8] A. Cavin, K. Hostettmann, W. Dyatmyko, and O. Potterat, "Antioxidant and lipophilic constituents of Tinospora crispa," Planta Medica, vol. 64, no. 5, pp. 393-396, 1998.

[9] J. C. Arcos and M. F. Argus, "Chemical induction of cancer," in Chemical Induction of Cancer: Structural Bases and Biological Mechanisms, vol. IIB, pp. 93-111, Academic Press, New York, NY, USA, 1974.

[10] U.S. Department of Health and Human Services, Registry of Toxic Effects of Chemical Substances (RTECS, Online Database), National Toxicology Information Program, National Library of Medicine, Bethesda, Md, USA, 1993.

[11] K. Hirao, Y. Shinohara, H. Tsuda, S. Fukushima, and M. Takahashi, "Carcinogenic activity of quinoline on rat liver," Cancer Research, vol. 36, no. 2, pp. 329-335, 1976.

[12] R. Hasegawa, F. Furukawa, K. Toyoda, H. Sato, K. Imaida, and M. Takahashi, "Sequential analysis of quinoline-induced hepatic hemangioendothelioma development in rats," Carcinogenesis, vol. 10, no. 4, pp. 711-716, 1989.

[13] S. Asakura, S. Sawada, T. Sugihara, H. Daimon, and F. Sagami, "Quinoline-induced chromosome aberrations and sister chromatid exchanges in rat liver," Environmental and Molecular Mutagenesis, vol. 30, pp. 459-467, 1997.

[14] E. J. LaVoie, S. Dolan, P. Little, C.-X. Wang, S. Sugie, and A. Rivenson, "Carcinogenicity of quinoline, 4- and 8-methylquinoline and benzoquinolines in newborn mice and rats," Food and Chemical Toxicology, vol. 26, no. 7, pp. 625-629, 1988.

[15] U.S. EPA, "Toxicilogical review of quinoline (CAS no. 91-22-5)," Tech. Rep. EPA/635/R-01/005, 2001.

[16] T. Sliwinski, A. Czechowska, M. Kolodziejczak, J. Jajte, M. Wisniewska-Jarosinska, and J. Blasiak, "Zinc salts differentially modulate DNA damage in normal and cancer cells," Cell Biology International, vol. 33, no. 4, pp. 542-547, 2009.

[17] L. Y. Y. Fong, K.-M. Lau, K. Huebner, and P. N. Magee, "Induction of esophageal tumors in zinc-deficient rats by single low doses of $\mathrm{N}$-nitrosomethylbenzylamine (NMBA): analysis of cell proliferation, and mutations in $\mathrm{H}$-ras and p53 genes," Carcinogenesis, vol. 18, no. 8, pp. 1477-1484, 1997.

[18] L. Y. Y. Fong, J. L. Farber, and P. N. Magee, "Zinc replenishment reduces esophageal cell proliferation and N-nitrosomethylbenzylamine (NMBA)-induced esophageal tumor incidence in zinc-deficient rats," Carcinogenesis, vol. 19, no. 9, pp. 1591-1596, 1998.

[19] F. Aqil, I. Ahmad, and Z. Mehmood, "Antioxidant and free radical scavenging properties of twelve traditionally used Indian medicinal plants," Turkish Journal of Biology, vol. 30, no. 3, pp. 177-183, 2006.

[20] Atlas Medical, “Total \& Direct Bilirubin for in-vitro diagnostic , DMSO. Colorimetric," Unit 4, William James House Cowley Rd, Cambridge, UK, CB4 0WX, Revision A, March 2007.

[21] J. Fehér and G. Lengyel, "Silymarin in the prevention and treatment of liver diseases and primary liver cancer," Current Pharmaceutical Biotechnology, vol. 13, no. 1, pp. 210-217, 2012.

[22] G. Reigh, H. McMahon, M. Ishizaki et al., "Cytochrome P450 species involved in the metabolism of quinoline," Carcinogenesis, vol. 17, no. 9, pp. 1989-1996, 1996.
[23] J. Fevery, "Bilirubin in clinical practice: a review," Liver International, vol. 28, no. 5, pp. 592-605, 2008.

[24] D. Schachter, "Nature of the glucuronide in direct-reacting bilirubin," Science, vol. 126, no. 3272, pp. 507-508, 1957.

[25] M. Muraca, J. Fevery, and N. Blanckaert, "Analytic aspects and clinical interpretation of serum bilirubins," Seminars in Liver Disease, vol. 8, no. 2, pp. 137-147, 1988.

[26] M. Hollstein, R. Talcott, and E. Wei, "Quinoline: conversion to a mutagen by human and rodent liver," Journal of the National Cancer Institute, vol. 60, no. 2, pp. 405-410, 1978.

[27] U.S. Environmental Protection Agency, Toxicological Review of Quinoline, U.S. Environmental Protection Agency, Washington, DC, USA, 2001.

[28] D. A. Cowan, L. A. Damani, and J. W. Gorrod, "Metabolic Noxidation of 3-substituted pyridines: identification of products by mass spectrometry," Biomedical Mass Spectrometry, vol. 5, no. 9, pp. 551-556, 1978.

[29] C.-C. Lin, D.-E. Shieh, and M.-H. Yen, "Hepatoprotective effect of the fractions of Ban-zhi-lian on experimental liver injuries in rats," Journal of Ethnopharmacology, vol. 56, no. 3, pp. 193-200, 1997.

[30] F. A. Kadir, F. Othman, M. A. Abdulla, F. Hussan, and P. Hassandarvish, "Effect of Tinospora crispa on thioacetamideinduced liver cirrhosis in rats," Indian Journal of Pharmacology, vol. 43, no. 1, pp. 64-68, 2011.

[31] P. Chavalittumrong, A. Attawish, A. Chuthaputti, and P. Chuntapet, "Toxicological study of crude extract of Tinospora crispa Mier ex," Thai Journal of Pharmaceutical Sciences, vol. 21, pp. 199-210, 1997.

[32] P. I. Oteiza, M. S. Clegg, M. P. Zago, and C. L. Keen, “Zinc deficiency induces oxidative stress and AP-1 activation in 3T3 cells," Free Radical Biology and Medicine, vol. 28, no. 7, pp. 10911099, 2000.

[33] D. A. Wiseman, S. M. Wells, M. Hubbard, J. E. Welker, and S. M. Black, "Alterations in zinc homeostasis underlie endothelial cell death induced by oxidative stress from acute exposure to hydrogen peroxide," American Journal of Physiology-Lung Cellular and Molecular Physiology, vol. 292, no. 1, pp. L165-L177, 2007. 

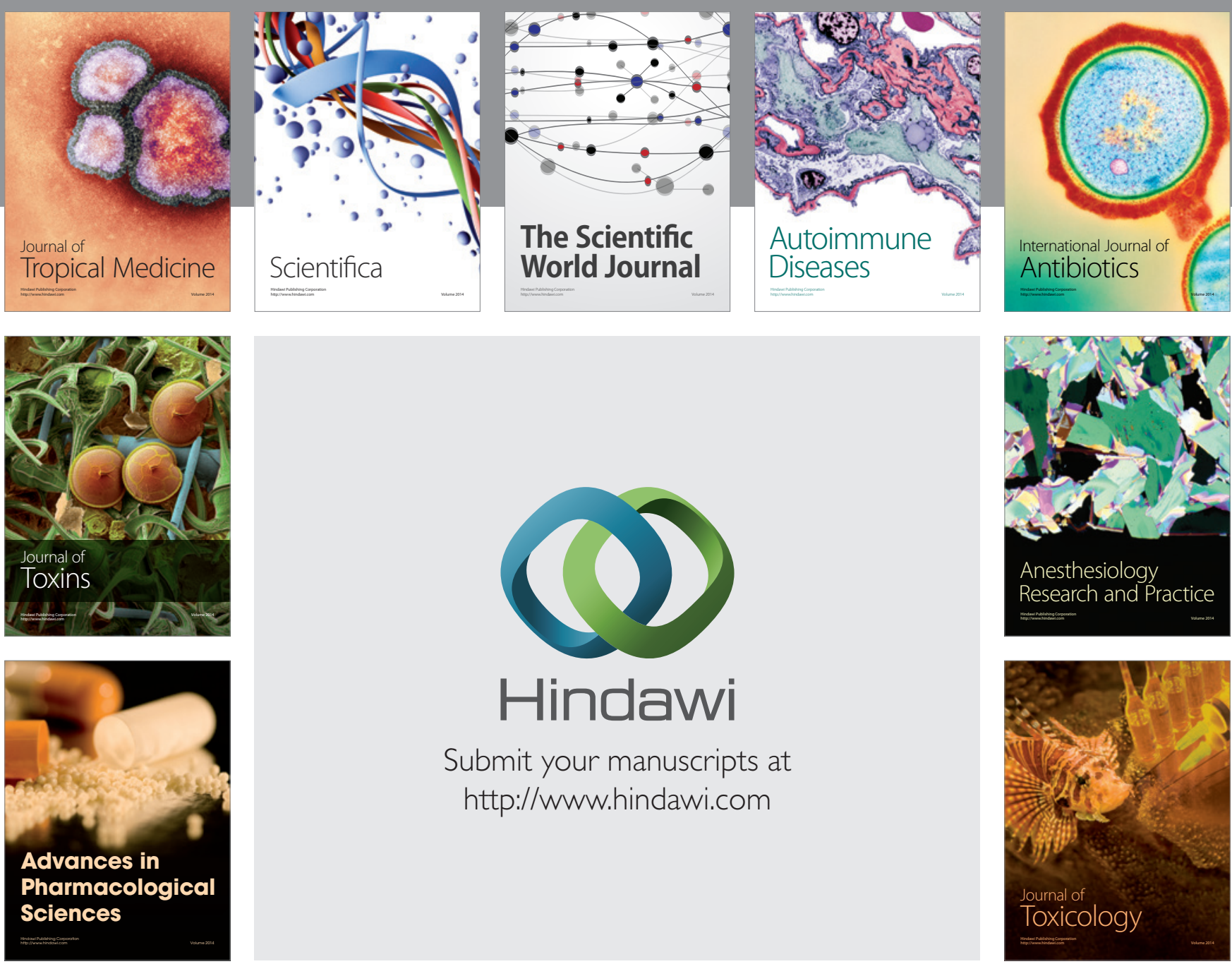

\section{Hindawi}

Submit your manuscripts at

http://www.hindawi.com
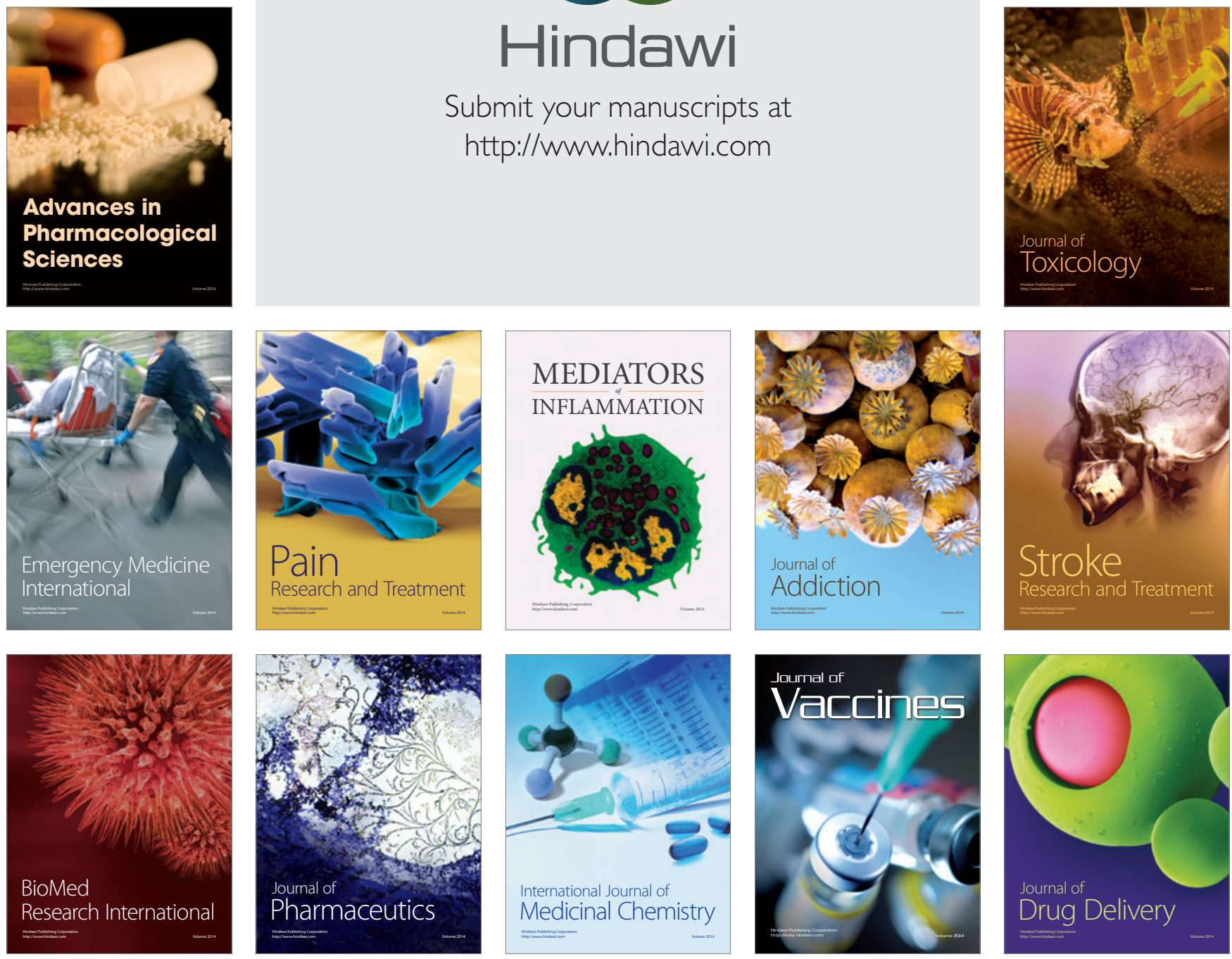